\title{
Calcium Release from Intra-Axonal Endoplasmic Reticulum Leads to Axon Degeneration through Mitochondrial Dysfunction
}

\author{
Rosario Villegas, ${ }^{1}$ Nicolas W. Martinez, ${ }^{1}$ Jorge Lillo, ${ }^{1}$ Phillipe Pihan, ${ }^{1}$ Diego Hernandez,,${ }^{1}$ Jeffery L. Twiss, ${ }^{2}$ \\ and Felipe A. Court ${ }^{1,3}$ \\ ${ }^{1}$ Millennium Nucleus for Regenerative Biology, Department of Physiology, Faculty of Biology, Pontificia Universidad Catolica de Chile, Santiago 8331150, \\ Chile, ${ }^{2}$ Department of Biological Sciences, University of South Carolina, Columbia, South Carolina 20208, and ${ }^{3}$ NeuroUnion Biomedical Foundation, \\ Santiago 7630614, Chile
}

Axonal degeneration represents an early pathological event in neurodegeneration, constituting an important target for neuroprotection. Regardless of the initial injury, which could be toxic, mechanical, metabolic, or genetic, degeneration of axons shares a common mechanism involving mitochondrial dysfunction and production of reactive oxygen species. Critical steps in this degenerative process are still unknown. Here we show that calcium release from the axonal endoplasmic reticulum (ER) through ryanodine and $\mathrm{IP}_{3}$ channels activates the mitochondrial permeability transition pore and contributes to axonal degeneration triggered by both mechanical and toxic insults in ex vivo and in vitro mouse and rat model systems. These data reveal a critical and early ER-dependent step during axonal degeneration, providing novel targets for axonal protection in neurodegenerative conditions.

Key words: axon degeneration; endoplasmic reticulum; mitochondria; mPTP; neurodegeneration

\section{Introduction}

Axonal degeneration is a common and early feature of several neurodegenerative conditions leading to functional impairment; therefore, it constitutes an important target for neuroprotection. Degeneration of axons can be triggered by toxic, mechanic, ischemic, and others types of insults in both central and peripheral nervous systems (CNS and PNS, respectively) and is conserved in different phyla (Coleman and Freeman, 2010), suggesting a preserved mechanism for the loss of neuronal extensions. Degeneration of axons triggered by nerve injury, known as Wallerian degeneration (Waller, 1850), has been used widely as a model to study the mechanisms associated with axon loss or degeneration in other neurodegenerative conditions (Coleman and Freeman, 2010).

It was suggested that axonal mitochondria represent a convergence point for several pro-degenerative stimuli leading to axonal degeneration (Court and Coleman, 2012). Specifically, the opening of the mitochondrial permeability transition pore (mPTP) is

Received Nov. 13, 2013; revised Feb. 26, 2014; accepted April 12, 2014.

Author contributions: R.V., J.L.T., and F.A.C. designed research; R.V., N.W.M., J.L., P.P., and D.H. performed research; N.W.M., J.L., P.P., D.H., and F.A.C. analyzed data; R.V., J.L.T., and F.A.C. wrote the paper.

This work was supported by National Fund of Scientific and Technological Development Grants 1070377 and 3130610 (R.V.), Millennium Nucleus Grant RC120003, Ring Initiative ACT1109 (F.A.C.), National Institutes of Health Grant R01-NS04156 and Dr. Miriam and Sheldon G. Adelson Medical Research Foundation (J.L.T.). We thank Monica Perez for excellent EM processing.

The authors declare no competing financial interests.

Correspondence should be addressed to Felipe Court, Department of Physiology, Faculty of Biology, Pontifical Catholic University of Chile, Avenida B. 0'Higgins 340, Santiago 8331150, Chile. E-mail: fcourt@bio.puc.cl; court.felipe@gmail.com.

DOI:10.1523/JNEUROSCI.4784-13.2014

Copyright $\odot 2014$ the authors $\quad 0270-6474 / 14 / 347179-11 \$ 15.00 / 0$ a key event during axonal degeneration, because MPTP inhibition strongly delays Wallerian degeneration (Barrientos et al., 2011) and possibly also contributes to axonal degeneration during neurodegenerative conditions, including multiple sclerosis, Alzheimer's disease, ALS, and cerebral ischemia (Schinzel et al., 2005; Forte et al., 2007; Du et al., 2008; Martin et al., 2009). mPTP opening is triggered by mitochondrial calcium overloading (Chappell and Crofts, 1965; Crompton and Costi, 1988) and oxidative stress (Broekemeier et al., 1992). Consistent with this mechanism of opening, systemic antioxidant treatment and upregulation of endogenous antioxidant mechanisms protect axons from degeneration (Calixto et al., 2012).

In addition to oxidative stress, an increase in mitochondrial calcium is fundamental for mPTP opening (Bernardi, 2013), and it is known that axotomy increases calcium in the axon above the normal range (Ziv and Spira, 1995). Moreover, filling the axon with calcium using ionophores can destroy the axon within a few hours (George et al., 1995), and extracellular calcium chelation prevents this degeneration (Stys et al., 1990). The current view is that the increase in axonal calcium from the extracellular milieu after a degenerative stimulus, including axotomy and blockage of axonal transport, activates calpains, contributing to the last steps of axonal disintegration. Nevertheless, after an ischemic insult, early inhibition of calcium release from internal stores inhibited the loss of axonal function (Stys, 2005), suggesting that more than one source of axonal calcium might be involved at different stages of the axonal degenerative program.

The endoplasmic reticulum (ER) is one the main intracellular compartments for calcium storage (Pozzan et al., 1994). In pe- 
ripheral axons, morphological evidences demonstrate that the ER forms a continuous network and establishes a close interaction with mitochondria (Tsukita and Ishikawa, 1976). Importantly, ER stress and calcium release from this organelle can induce mPTP opening in other cell types (Deniaud et al., 2008). Nevertheless, the role of the axonal ER in physiological and degenerative process in the axonal compartment is not fully understood.

Here we show that calcium release from axonal ER stores is involved in degeneration of axons triggered by mechanical injury and toxic insults. ER-derived calcium from ryanodine (RyaR) and $\mathrm{IP}_{3}$ $\left(\mathrm{IP}_{3} \mathrm{R}\right)$ receptors activates the $\mathrm{mPTP}$ and contributes to axonal degeneration in both cultured neurons and ex vivo nerve preparations. This is the first report to demonstrate the relevance of an ERdependent calcium release in axonal degeneration and suggests that proper functioning of the ER in the axonal compartment is required for axonal viability.

\section{Materials and Methods}

Animals

Pregnant Sprague Dawley rats (150 g) and C57BL/6J mice (11 weeks old, 20-25 g) strain of either sex were obtained from the P. Catholic University animal house. Experiments with animals followed protocols approved by the Institutional Animal Care and Use Committees and complied with National Institutes of Health guidelines.

\section{Nerve explant cultures}

To study axonal degeneration ex vivo, $5 \mathrm{~mm}$ sciatic nerve segments were dissected from adult mice and cultured in 24-well dishes containing $400 \mu \mathrm{l}$ of Neurobasal medium (Invitrogen), 2\% B27 (Invitrogen), 0.3\% L-glutamine, and $1 \%$ streptomycin/penicillin. Explants were cultured at $37^{\circ} \mathrm{C}$ and $5 \% \mathrm{CO}_{2}$ for up to $3 \mathrm{~d}$, with daily changes of media supplemented with drug or corresponding vehicle as control. In previous studies, these nerve explants required a drug concentration at least one order of magnitude higher than dissociated cultures to obtain similar effects (Court et al., 2009; Barrientos et al., 2011). This is probably because of the presence of the hematoneural barrier of the nerve (epineurium, perineurium, and collagen and extracellular matrix of the endoneurium) and myelinating Schwann cells. The following drugs were used: cyclosporine A (CsA; catalog \#30024; Sigma Aldrich), 6-hydroxy-2,5,7,8-tetramethylchroman-2-carboxylic acid (Trolox; catalog \#648471; Merck), 3,8-phenanthridinediamine (Dihydroethydium; catalog \#D1168; Invitrogen), EGTA (catalog \#E3889; Sigma-Aldrich), 1,2-bis(2-aminophenoxy)ethane- $N, N, N^{\prime}, N^{\prime}$-tetraacetic acid tetrakis(acetoxymethyl ester) (BAPTA-AM; catalog \#B6769; Invitrogen), Rya (catalog \#559276; Calbiochem), ruthenium (Ru360; catalog \#557440; Calbiochem), U73122 (1-[6[[(17 $\beta$ )-3-methoxyestra-1,3,5(10)-trien-17-yl] amino]hexyl]-1 Hpyrrole-2,5-dione) (catalog \#U6756; Sigma), and caffeine (catalog \#C0750; Sigma).

\section{Dorsal root ganglion cultures}

Briefly, E16 rat embryos were decapitated, and the vertebral column was removed. The spinal cord with dorsal root ganglia (DRGs) was dissected and placed in a Petri dish containing L-15 medium. For DRG explants, complete DRGs were cultured in 24-well dishes containing $400 \mu \mathrm{l}$ of
Neurobasal medium (Invitrogen), 2\% B27 (Invitrogen), 0.3\% L-glutamine, $1 \%$ streptomycin/penicillin, $4 \mu \mathrm{M}$ aphidicolin, $7.5 \mu \mathrm{g} / \mathrm{ml}$ 5-fluoro-2- deoxyuridine, and $50 \mathrm{ng} / \mathrm{ml} \mathrm{NGF}$. The mixture of aphidicolin and fluoro-2-deoxyuridine inhibits proliferation of Schwann cells by inhibition of DNA polymerase (Spadari et al., 1985; Wallace and Johnson, 1989), and DRGs cultivated in these conditions seldom contain Schwann cells (Heermann et al., 2012). DRGs were cultured for $7 \mathrm{~d}$ at $37^{\circ} \mathrm{C}$ and $5 \% \mathrm{CO}_{2}$. At day 7 , ganglia were excised using a micropipette tip. This procedure eliminated all neuronal somas from the ganglia. For dissociated culture, DRGs were freed from the connective tissue sheaths and incubated with $2.0 \mathrm{mg} / \mathrm{ml}$ trypsin for $30 \mathrm{~min}$ at $37^{\circ} \mathrm{C}$. After trypsinization, cells were gently triturated with fire-polished Pasteur pipettes in serum containing media and then placed in poly-D-lysine $(0.1 \mathrm{mg} / \mathrm{ml})$ coated $35 \mathrm{~mm}$ culture plates and incubated at $37^{\circ} \mathrm{C}$ with $95 \%$ relative humidity and $5 \% \mathrm{CO}_{2}$. The degeneration index was based on the ratio of the areas of fragmented axons versus total axonal area (Araki et al., 2004; Sasaki et al., 2009). Degenerated axon fragments were detected using the particle analyzer algorithm of NIH ImageJ, and the total fragmented axon area versus total axonal area was used to estimate a degeneration index.

\section{Immunofluorescence and electron microscopy of sciatic nerves} For immunofluorescence analyses, sciatic nerves were fixed by immersion in $4 \%$ paraformaldehyde in $0.1 \mathrm{~m}$ PBS $(1 \times \mathrm{PBS}, \mathrm{pH} 7.4)$ for $1 \mathrm{~h}$, followed by three $10 \mathrm{~min}$ washes in $1 \times$ PBS, sucrose gradient (5, 10 , and $20 \%$ in $1 \times \mathrm{PBS}$ ), and then embedded in OCT (catalog \#25608-930; Sakura Finetek). Cryostat sections from the middle of the explants were cut transversely at $10 \mu \mathrm{m}$ thickness and mounted on 
A 0 days

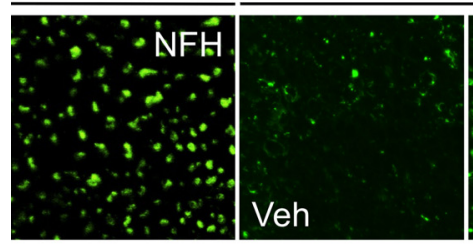

C $0 \mathrm{~h}$

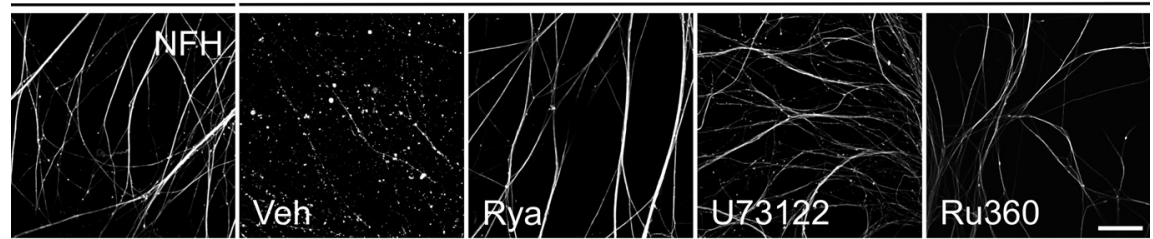

$\mathrm{B}$

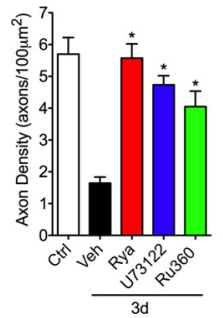

D

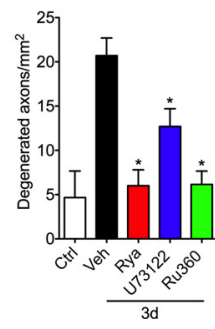

Figure 2. Pharmacological inhibition of ER calcium channels protects axotomy-induced axonal degeneration. Sciatic nerve explants from mice were incubated in vehicle (Veh) solution, Rya $(50 \mu \mathrm{M}), \mathrm{U} 73122(20 \mu \mathrm{m})$, or Ru360 $(50 \mu \mathrm{m})$ for $3 \mathrm{~d}$ and analyzed by immunofluorescence. $A$, Transverse sections of nerve explants stained for NFH. Axons in nerve explants incubated for $3 \mathrm{~d}$ with Rya, U73122, or Ru360 do not show signs of degeneration. Scale bar, $20 \mu \mathrm{m}$. B, Quantification of axons positive for NFH in explant cross-sections as shown in $A$, expressed as axons per $100 \mu \mathrm{m}^{2}$. Statistically significant protection is seen after Rya, U73122, or Ru360 treatment at $3 \mathrm{~d}$ ( ${ }^{*} p<0.05$ by Student's $t$ test compared with $3 \mathrm{~d}$ of vehicle; error bars indicate SEM). C, Embryonic DRG explants in vitro were axotomized and treated with Rya $(5 \mu \mathrm{M})$, U73122 $(2 \mu \mathrm{M})$, or Ru360 $(5 \mu \mathrm{M})$. At $12 \mathrm{hpa}$, cultures were immunostained for NFH. Treatment with Rya, U73122, or Ru360 protects axons from axotomy-induced degeneration. Scale bar, 50 $\mu \mathrm{m} . \boldsymbol{D}$, Quantification of axonal preservation by the degeneration index (area neurites fragmented/total area; for details, see Materials and Methods). Rya, U73122, or Ru360 protects injury-induced neurite degeneration at $12 \mathrm{hpa}(n=9,3$ images per sample, 3 samples per condition, 3 repetitions; ${ }^{*} p<0.05$ by Student's $t$ test compared with control; error bars indicate SEM).

Superfrost Plus slides (catalog \#4951PLUS; Thermo Fisher Scientific). Sections were washed in $1 \times$ PBS for $10 \mathrm{~min}$ and then blocked/permeabilized in $0.1 \%$ Triton $\mathrm{X}-100,2 \%$ gelatin from cold-water fish (catalog \#G7765; Sigma-Aldrich) in $1 \times$ PBS for $1 \mathrm{~h}$ at room temperature (RT). Sections were incubated in primary antibodies in blocking/ permeabilizing solution overnight at $4^{\circ} \mathrm{C}$, washed in $1 \times$ PBS three times for $10 \mathrm{~min}$, and incubated in secondary antibodies for $2 \mathrm{~h}$ at RT. Sections were washed three times for $10 \mathrm{~min}$ in $1 \times$ PBS and mounted in Vectashield (Vector Laboratories). The number of axons per area of nerve tissue was assessed in images of neurofilament-immunostained explant sections using the particle analysis macro of NIH ImageJ. The following antibodies were used for immunofluorescence: rabbit antineurofilament heavy chain (NFH; catalog \#N4142; Sigma-Aldrich) at 1:1000; donkey anti-rabbit TRITC (catalog \#711-025-152; Jackson ImmunoResearch) at 1:300; and goat anti-chicken FITC (catalog \#A-21449; Invitrogen) at 1:300.

For electron microscopy (EM) analyses, nerves were fixed overnight by immersion in $2.5 \%$ glutaraldehyde, $0.01 \%$ picric acid, and $0.1 \mathrm{M}$ cacodylate buffer, $\mathrm{pH}$ 7.4. Nerves were rinsed in the same buffer, immersed in $1 \% \mathrm{OsO} 4$ for $1 \mathrm{~h}$, followed by en bloc incubation with $2 \%$ uranyl acetate for $2 \mathrm{~h}$. Nerves were dehydrated with a graded series of ethanol and propylene oxide and infiltrated with Epon (catalog \#18010; Ted Pella). Ultrathin sections from the middle of the explants were contrasted with $1 \%$ uranyl acetate and lead citrate. Grids were examined with a Philips Tecnai 12 electron microscope operated at 80 $\mathrm{kV}$. Negative films were developed and scanned. For quantification of axonal degeneration at the EM level, we include in the category of degenerated axons those with collapsed myelin sheaths or axoplasm with undefined cytoskeletal structures and those that are less electron dense than control ones.

\section{$3 D$ reconstruction}

Tissue processing. For three-dimensional reconstruction at the EM level, nerves were fixed in $3 \%$ glutaraldehyde in $0.05 \mathrm{M}$ cacodylate buffer with $0.05 \%$ picric acid for $24 \mathrm{~h}$ at $4^{\circ} \mathrm{C}$. After washing in cacodylate buffer, nerves were treated with $1 \%$ osmium tetroxide with $1.5 \%$ potassium ferrocyanide for $1 \mathrm{~h}$. After washes in distilled water, nerves were immersed in $2 \%$ aqueous uranyl acetate for $1 \mathrm{~h}$. Nerves were dehydrated and embedded with a Eponate 12 embedding kit (cata$\log \# 18010$; Ted Pella).

Ultramicrotomy and EM. Serial sections $\sim 100 \mathrm{~nm}$ were obtained and mounted in carbon Formvar-coated slot grids. Thin sections were contrasted using uranyl acetate and lead citrate. Observations of the grids were made using a Phillips Tecnai 12 Biotwin electron microscope; sequential photographs were taken and processed as described below.

Image processing. Single photographs of the series were merged, and the stack was registered using the newstack and midas tools of the IMOD 3D rendering software (Kremer et al., 1996). The aligned stack was opened with the TrakEM2 plugin (Saalfeld et al., 2010, 2012) using the software Fiji (Schindelin et al., 2012). For the 3D reconstruction, manual tracing of the structures of interest was performed and rendered in 3D representation after edge smoothing.

\section{Small interfering $R N A$ reagents and transfection}

We used the pooled SMART-selecte small interfering RNAs (siRNAs; Dharmacon) for targeting RyaR1 (L-082079-01-0005), RyaR3 (L-092028-01-0005), and $\mathrm{IP}_{3} \mathrm{R} 1 \mathrm{mRNA}$ (L095360-01-0005). For control transfections, the control nontargeting siRNA (Dharmacon), which was designed with at least four mismatches to any known human or mouse gene, was used. Cells were transfected with 100 or $200 \mathrm{~nm}$ siRNAs using DharmaFect reagent (catalog \#T-2003-02; Thermo Fisher Scientific) following the instructions of the manufacturer.

\section{Quantitative RT-PCR analyses}

Dissociated DRG neurons transfected with siRNA pools were analyzed at $3 \mathrm{~d}$ after transfection. RNA was extracted by the RNAeasy kit (catalog \#74104; Qiagen), quantified, and reverse transcribed using Promega GoTag. Reverse-transcribed RNA samples were then amplified by quantitative PCR (qPCR) using the SybrGreen kit (catalog \#; QT 605-05; Bioline Reagents). Primers used included the following: IP ${ }_{3} \mathrm{R} 1$, forward, GAGATGAGCCTGGCTGAGGTTCAA; reverse, TGTTGCCTCCTTCCAGAAGTGCGA; RyaR1, forward, TCTTCCCTGCTGGAGACTGT; reverse, TGGGAGAAGGCACTTGAGG; and RyaR3, forward, TCTTCCCTGCTGGAGACTGT; reverse, GTCTCCATGTCTTCCCGTA. Conditions for establishing the dissociation curves of the fluorophore with the amplified products were $10 \mathrm{~min}$ at $95^{\circ} \mathrm{C}, 5 \mathrm{~min}$ at $25^{\circ} \mathrm{C}$, and then cycling for $1 \mathrm{~min}$ at $70^{\circ} \mathrm{C}$ and $1 \mathrm{~min}$ at $95^{\circ} \mathrm{C}$. The relative levels of mRNA were normalized to rat GAPDH mRNA as an internal control $\left(\Delta \mathrm{C}_{\mathrm{T}}\right)$, and RNA levels were then expressed relative to nontargeted siRNA control treated cells $\left(\Delta \Delta \mathrm{C}_{\mathrm{T}}\right)$.

\section{Tetramethylrhodamine methyl ester measurements of mitochondrial membrane potential}

Tetramethylrhodamine methyl ester (TMRM; catalog \#T-668; Invitrogen) is a cell-permeant, fluorescent dye that is readily sequestered by active mitochondria and then released from mitochondria during depolarization (Blattner et al., 2001). TMRM was added to a final concentra- 
A $0 \mathrm{~h}$

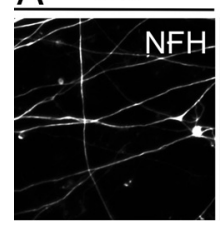

C $0 \mathrm{~h}$

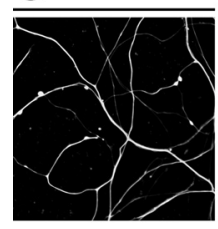

B

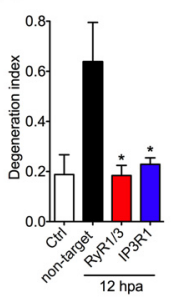

$12 \mathrm{hpa}$ in vitro

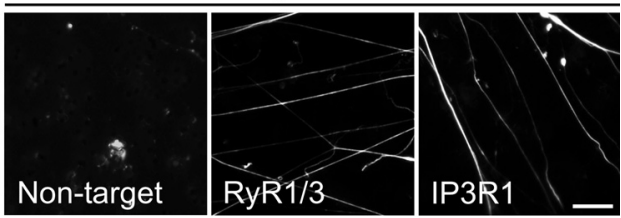

$12 \mathrm{~h}$ vinblastine in vitro

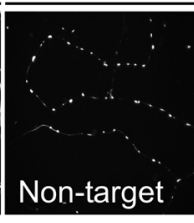

$\mathrm{D}$

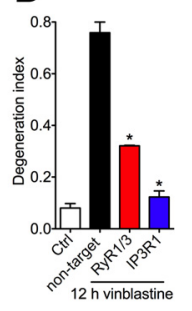

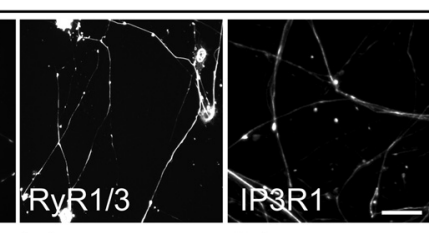

E $\underset{\substack{\text { Non- } \\ \operatorname{target} R y R 1}}{F}$ F

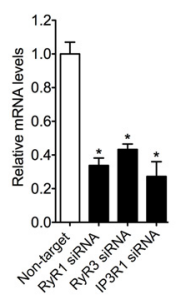

Figure 3. Genetic knockdown of RyaR and $\mathrm{IP}_{3} \mathrm{R} 1$ protects degeneration of mechanically or toxic injured axons. An siRNA pool was used to determine whether depletion of RyaR1 and RyaR3 (RyR1/3) or IP ${ }_{3} R 1$ from dissociated DRG cultures protect from axotomy and vincristinetriggered axonal degeneration. DRGs were transfected with the siRNA pool or a control (Ctrl) nontargeting siRNA. A, Transfected DRG neurons were cultured on transwell chambers, allowing the separation of axonal processes from cell bodies. After $72 \mathrm{~h}$ of culture, neuronal cell bodies were scraped away from the upper membrane surface. Control siRNA-transfected neurons showed almost complete degeneration of distal axon $12 \mathrm{~h}$ after transection, but RyaR1/3 and $\mathrm{IP}_{3} \mathrm{R} 1$ siRNA transfected neurons showed preservation of axons over the same period of time. Scale bar, $50 \mu \mathrm{m}$. C, DRGs were transfected as in $A$ and treated with vincristine $(1 \mu \mathrm{M})$ to induce axonal degeneration. Both RyaR1/3 and IP $\mathrm{R} 1$ siRNA-transfected neurons showed preservation of axons $12 \mathrm{~h}$ after vincristine treatment. $\boldsymbol{B}, \boldsymbol{D}$, Quantification of injury-induced degeneration of $\boldsymbol{A}$ and $\boldsymbol{C}$ using the degeneration index ( $n=9,3$ images per sample, 3 samples per condition, 3 repetitions; ${ }^{*} p<0.05$ by Student's $t$ test compared with nontarget siRNA; error bars indicate SEM). $E$, Reduction of RyaR1, RyaR3, and IP $R 1$ mRNA after siRNA was assessed by qPCR in embryonic DRG neurons. $E, F$, Gel bands of each qPCR result. A significant decrease of RyaR1, RyaR3, and IP ${ }_{3}$ R1 mRNA was observed after siRNA ( $n=3$ per each group; ${ }^{*} p<0.05$ by Student's $t$ test compared with nontarget siRNA; error bars indicate SEM).

tion of $1 \mu \mathrm{M}$ in HBSS and incubated for $30 \mathrm{~min}$ at $37^{\circ} \mathrm{C}$ protected from light. TMRM fluorescence was determined at 0 and $6 \mathrm{~h}$ post axotomy (hpa) using a spinning disk microscope (544 nm excitation and $590 \mathrm{~nm}$ emission filters). Change in fluorescence levels after different treatments were normalized to non-axotomized controls.

\section{Intracellular calcium measurements in DRG neurons}

DRG cell cultures were loaded for $30 \mathrm{~min}$ at $37^{\circ} \mathrm{C}$ in the dark with the cell-permeant AM of the fluorescent $\mathrm{Ca}^{2+}$ indicator fura-2 $(5 \mu \mathrm{M})$. Simultaneously, cells were exposed to different drugs (Rya and U73122). To remove excess extracellular fura-2, glass coverslips were washed three times with HBSS. Intracellular fura- 2 was alternately excited at 340 and $380 \mathrm{~nm}$, and the emitted light was measured at a wavelength of $510 \mathrm{~nm}$. The fluorescence ratio $(340 / 380)$ provides a relative measure of the cytosolic-free $\mathrm{Ca}^{2+}$ concentration $\left(\left[\mathrm{Ca}^{2+}\right]_{\mathrm{i}}\right)$.

\section{Reactive oxidative species measurements}

Immediately after axotomy, DRGs were incubated with standard culture medium plus one of the following drugs: $10 \mu \mathrm{M}$ Trolox, $20 \mu \mathrm{M}$ CsA, $2 \mu \mathrm{M}$ U73122, $5 \mu \mathrm{M}$ Rya, or $5 \mu \mathrm{M}$ Ru360. Superoxide levels were measured using dihydroethidium (DHE) fluorescence $6 \mathrm{~h}$ after DRG axotomy in an epifluorescence microscope. Neurites were incubated in the last $30 \mathrm{~min}$ with $5 \mu \mathrm{M}$ DHE under culture conditions. DHE fluorescence was obtained under a Cy5 emission filter. Superoxide levels on neurites were

determined using NIH ImageJ colocalization highlighter plugin. Oxidative stress levels were calculated as the ratio of DHE fluorescent signal area in neurites and neurite length in every condition. Briefly, DHE signal and phase-contrast colocalization were used to obtain DHE area and neurite length. Photoshop (Adobe Systems) and NIH ImageJ were used to perform this analysis.

Analysis of ATP levels

Intraneuritic levels of ATP were assessed using magnesium green $(\mathrm{Mg}$ Green; catalog \#M-3735; Invitrogen) indicator (Persson et al., 2013). In 7 DIV DRGs, MgGreen was added to a final concentration of $5 \mu \mathrm{M}$ in HBSS and incubated for $30 \mathrm{~min}$ at $37^{\circ} \mathrm{C}$ protected from light. MgGreen fluorescence was determined at 0 and 6 hpa using a spinning disk microscope $(488 \mathrm{~nm})$. Change in fluorescence levels after different treatments were normalized to non-axotomized controls.

\section{Results}

\section{Intracellular and extracellular calcium participates in the} axonal degeneration cascade

To study the role of calcium in axonal degeneration, we first used an ex vivo model of injury-induced axonal degeneration of sciatic nerve explants, without contribution of the neuronal soma or the infiltrating immune cells, in which pharmacological treatments are well achieved and axonal degeneration can be readily evaluated (Tsao et al., 1999; Barrientos et al., 2011). In this model, we determined previously by Western blot and immunofluorescence that, at $3 \mathrm{~d}$ after injury, most axons in the nerve explant have degenerated (Barrientos et al., 2011).

Nerve explants were incubated for $3 \mathrm{~d}$ with the intracellular or extracellular calcium chelators BAPTA-AM or EGTA, respectively, and the degree of axonal degeneration was analyzed by immunofluorescence against neurofilament (NFH) that we characterized previously as a reliable readout for axonal degeneration in these explants (Barrientos et al., 2011). Compared with vehicle-treated sciatic nerve explants, both calcium chelators strongly protected from injury-induced axonal degeneration as shown by immunofluorescent images (Fig. 1A). Quantification of the axon density across multiple experiments (see Materials and Methods) showed significant protection from calcium chelation (Fig. 1B). These results confirm previous studies demonstrating that axonal degeneration is a calcium-dependent process (Schlaepfer and Bunge, 1973; George et al., 1995).

Axonal degeneration requires $\mathrm{mPTP}$ opening (Barrientos et al., 2011). Because calcium is one of the main mPTP activators, this ion might be acting early after nerve injury in the cascade leading to axonal degeneration by activating the MPTP. Swelling of the axonal mitochondria attributable to the increase of mitochondria permeability represents a reliable ultrastructural indicator of mPTP opening (Hunter et al., 1976). This swelling takes place early during axonal degeneration (Vial, 1958; Webster, 1962; Barrientos et al., 2011). To test the effect of calcium chelation on mPTP opening, we measured mitochondrial diameter in sciatic nerve explants treated for $3 \mathrm{~d}$ with BAPTA-AM or EGTA. BAPTA-AM and EGTA protected axons from degeneration judged by both neurofilament immunofluorescence (Fig. $1 A, B$ ) and ultrastructural analyses (Fig. 1C). Surprisingly, mitochondrial diameter was differentially affected by intracellular or extracellular calcium chelation. Chelation of intercellular calcium by BAPTA-AM significantly inhibited swelling, but extracellular calcium chelation by EGTA had no significant effect on mitochondrial swelling compared with vehicle-treated explants (Fig. 1C,D).

These results show that chelation of external calcium can protect from neurofilament degradation and axonal disintegration and suggest that mPTP is activated by calcium released from internal stores. 

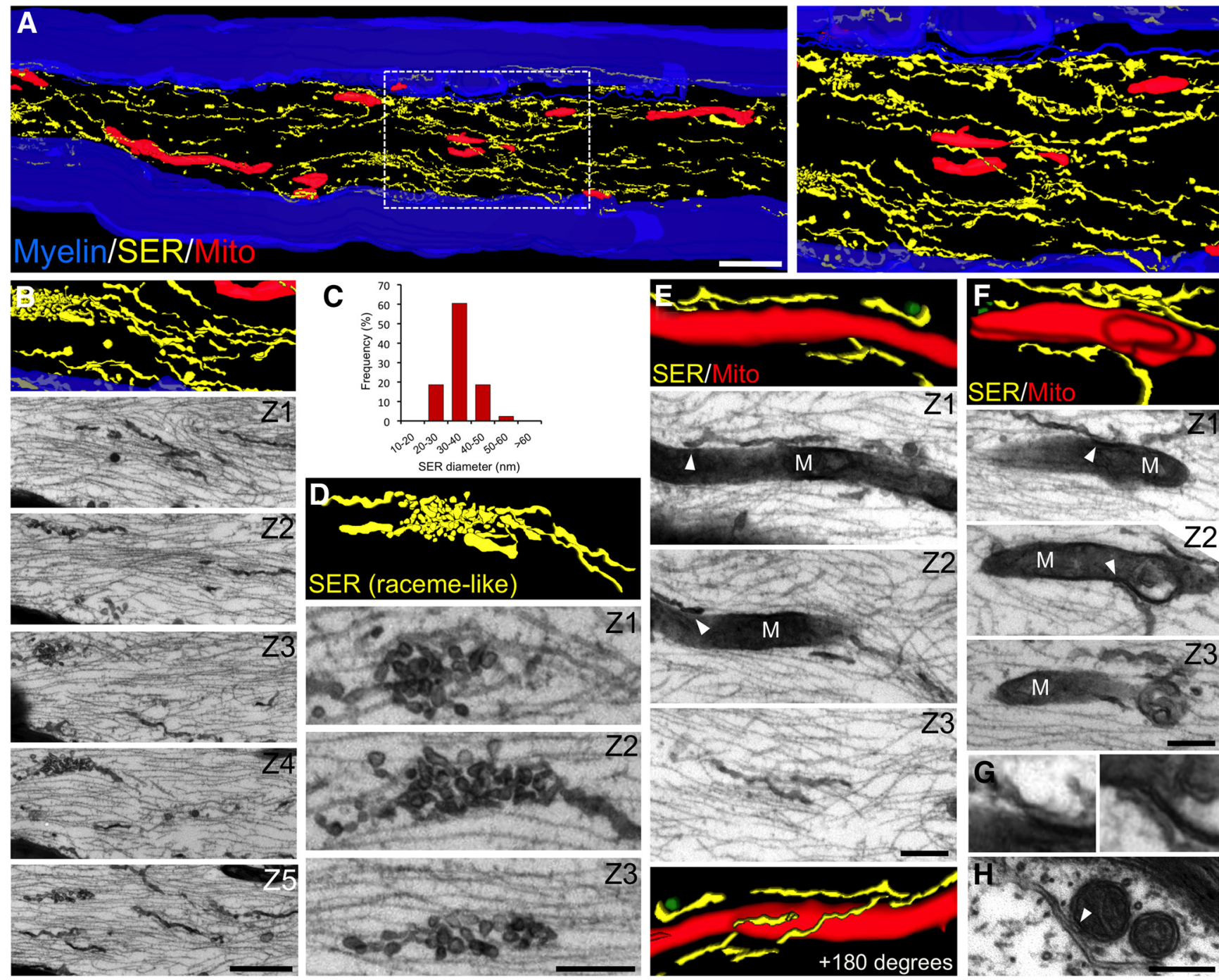
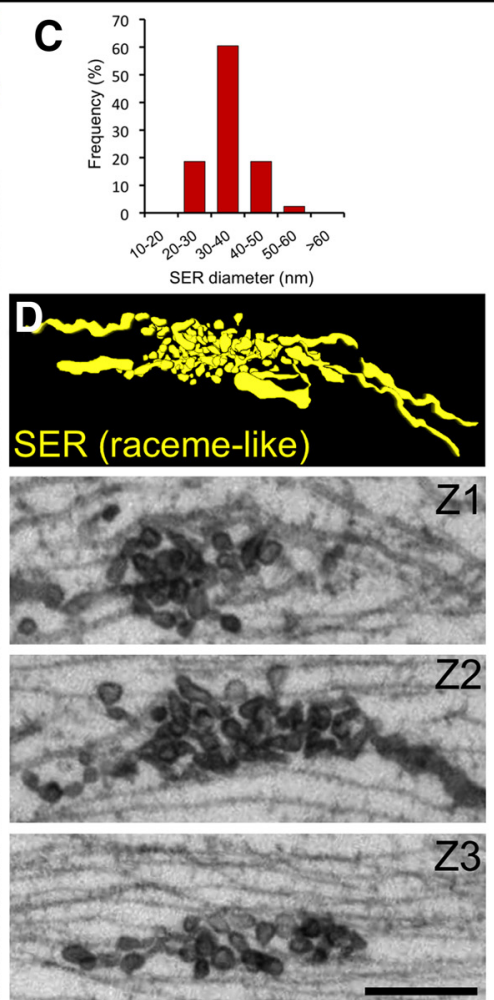
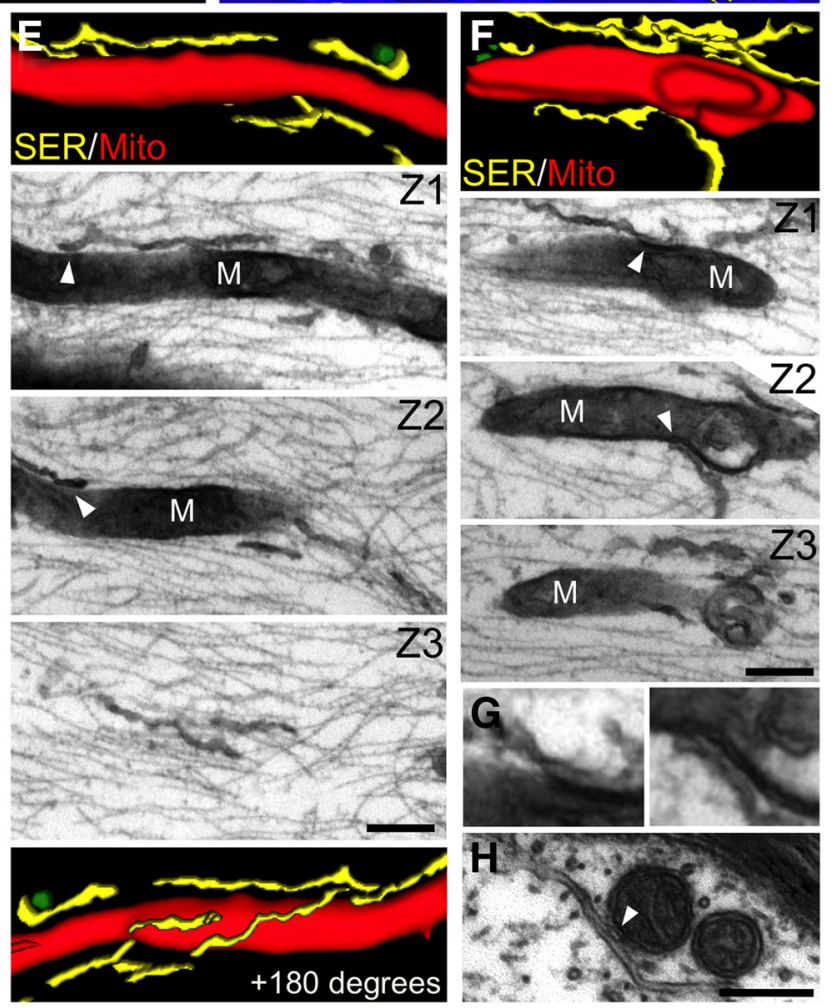

Figure 4. 3D axon reconstruction shows close appositions between mitochondria and ER organelles in peripheral axons. Sciatic nerves from wild-type mice were fixed, and serial sections at $\sim 80$ $\mathrm{nm}$ intervals were obtained (see Materials and Methods). After section alignment, axonal membrane structures and mitochondria were reconstructed from myelinated fibers and rendered. Reticular structures are colored yellow, mitochondria in red, and the myelin sheath in blue. Selected micrographs from contiguous sections are included for each rendering. $A$, $3 D$ reconstruction shows an extensive smooth endoplasmic reticulum (SER) network and elongated mitochondria of varying sizes. The right shows a higher magnification of the boxed area from the left. C, Quantification of axonal SER diameter. Different types of morphological configurations of the SER network are observed, including fibrillar (B) and specializations in the form of raceme-like structures (D). $\boldsymbol{E}, \boldsymbol{F}$, Regions of close proximity between mitochondria (M) and SER in the axonal compartment (see arrowheads in individual sections). $\boldsymbol{G}$, Higher magnification of regions indicated by arrowheads in $\boldsymbol{F}$. $\boldsymbol{H}$, Cross-section of a myelinated axon in which a SER structure is closely apposed to two mitochondria. Scale bars, $\boldsymbol{A}, 1 \mu \mathrm{m} ; \boldsymbol{B}, 500$ $\mathrm{nm} ; \boldsymbol{D}, 250 \mathrm{~nm} ; \boldsymbol{E}, \boldsymbol{F}, 200 \mathrm{~nm} ; \boldsymbol{H}, 200 \mathrm{~nm}$.

Early calcium increase after axotomy is dependent on ER calcium channels

Axonal degeneration is a calcium-mediated event (Schlaepfer, 1974). It is well known that calcium activates proteases during the late stages of Wallerian degeneration (Schlaepfer and Hasler, 1979), and an early increase in intra-axonal calcium levels was described recently in primary cultures of axotomized sensory axons (Adalbert et al., 2012).

To study the role of intracellular calcium stores in the degeneration of axons, we first analyzed the effects of pharmacological inhibition of ER calcium channels on intra-axonal calcium levels after axotomy. We used cultures of sensory neurons from dorsal root ganglia (DRGs) devoid of Schwann cells (Lopez-Verrilli et al., 2013) and the fluorescent calcium indicator fura-2 for these studies. Compared with sciatic nerve explant, DRG neurons in vitro show very different timing of degeneration (Barrientos et al., 2011). We studies the time course of degeneration for DRG neu- rites after axotomy, and by $12 \mathrm{~h}$, most axotomized DRG neurites were degenerated (data not shown). To test the contribution of intracellular calcium stores during Wallerian degeneration, we blocked RyaR or $\mathrm{IP}_{3} \mathrm{R}$, which both function as ER calcium channels, using Rya or the phospholipase C inhibitor U73122, respectively. In these DRG neurons, axotomy results in a potent calcium increase in neurites at 6 hpa when compared with intact DRGs (Fig. 1E,F). Incubating DRGs with Rya or U73122 primarily prevented this calcium increase in injured DRGs (Fig. $1 E, F$ ). Together, these results indicated that calcium release from both RyaR and $\mathrm{IP}_{3} \mathrm{R}$ contributes to the early calcium increase after axotomy.

ER calcium channel blockers inhibit injury-induced axonal degeneration

In the cytoplasm, most calcium is sequestered in organelles, such as the ER and mitochondria, or bound to calcium-binding proteins. To test the contribution of ER calcium during Wallerian 
degeneration, we blocked the ER calcium channels using Rya or U73122.

Incubating nerve explants with Rya or U73122 significantly protects from axonal degeneration (Fig. 2A,B). To determine whether the protective effect of these drugs targets the axonal ER, we used DRG neurons devoid of Schwann cells (see Materials and Methods). After mechanical transection of DRG axons, degeneration of anucleated axons in vehicle-treated cultures was complete by 12 hpa based on NFH immunostaining (Fig. 2C). However, anucleated axons treated with Rya or U73122 appeared intact at $12 \mathrm{~h}$ (Fig. 2C). Quantifying the axonal degeneration index (see Materials and Methods) showed a significant decrease in degeneration for the Rya- and U73122treated cultures (Fig. 2D). This protection seen with inhibition of RyaR and $\mathrm{IP}_{3} \mathrm{R}$ was comparable with that seen Ru360 that inhibits mitochondrial calcium uptake (Fig. $2 B, D)$. Together, these results suggest that calcium release from either RyaR or $\mathrm{IP}_{3} \mathrm{R}$ in the axonal ER participates in axonal degeneration.

\section{Genetic knockdown of ER calcium channels protects against axonal degeneration}

To genetically test the contribution of ER calcium channels in axonal degeneration, we specifically depleted neurons of RyaR and $\mathrm{IP}_{3} \mathrm{R}$ using siRNA. In mammals, there are three RyaR isoforms and five $\mathrm{IP}_{3} \mathrm{R}$ isoforms (Ross et al., 1992). RyaR1, RyaR3, and $\mathrm{IP}_{3} \mathrm{R} 1$ are expressed in rat DRGs (Dent et al., 1996; Cheng et al., 2010).

To obtain higher transfection efficiency, we use dissociated DRG cultures cultured in transwell chambers, in which DRG neurons are seeded in the top compartment and extend neurites across a porous membrane to the lower compartment (Zheng et al., 2001). This approach was used previously to quantify axonal degeneration in DRG cultures (Schoenmann et al., 2010; Barrientos et al., 2011). Axotomy is performed by scraping away cell bodies, leaving isolated axons associated with the chamber membrane in the lower compartment. DRG neurons were transfected and neurite integrity was analyzed by immunostaining $12 \mathrm{hpa}$. RT-PCR showed that each siRNA pool specifically and significantly reduced mRNA levels of its target $3 \mathrm{~d}$ after transfection (Fig. 3 E,F). The knockdown of either RyaR1/3 or $\mathrm{IP}_{3} \mathrm{R} 1$ strongly protected from the axonal degeneration induced by axotomy (Fig. $3 A, B$ ).

To determine whether RyaR $1 / 3$ and $\mathrm{IP}_{3} \mathrm{R} 1$ play a role in axon degeneration from other stimuli, we used the chemotherapeutic agent vinblastine that disrupts microtubule-based axonal transport and triggers axonal degeneration in intact neurons (Ikegami and Koike, 2003). After depletion of either RyaR $1 / 3$ or $I_{3} R 1$, axons were significantly protected from this chemical-induced axonal degeneration paradigm based on NF immunostaining (Fig. 3C,D).

Together, the above data indicate that chemical-induced axon degeneration and axotomy-induced Wallerian degeneration use mechanisms that require activation of both RyaR and $I_{3} R$.
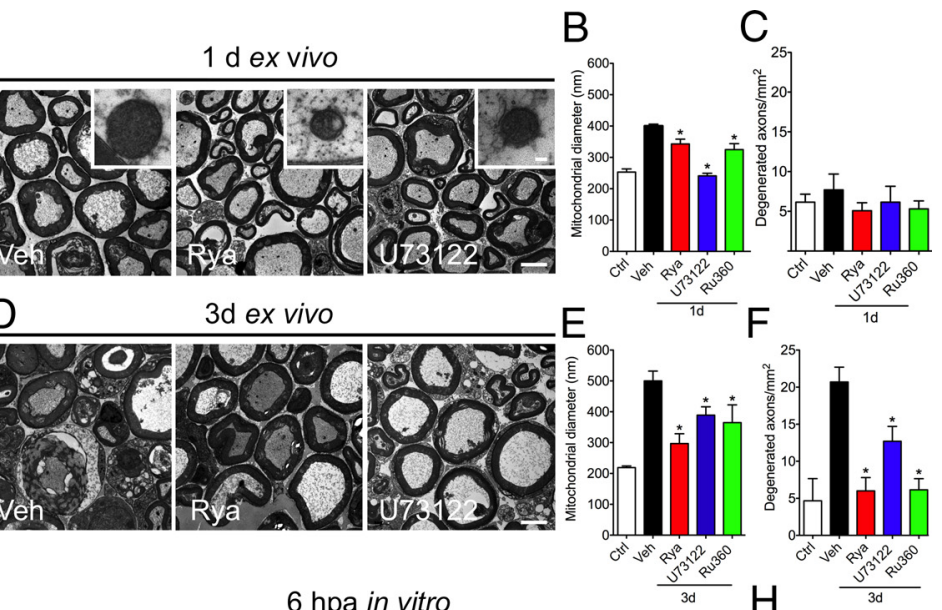

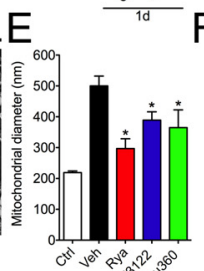

F

$1 \mathrm{~d}$ ex vivo

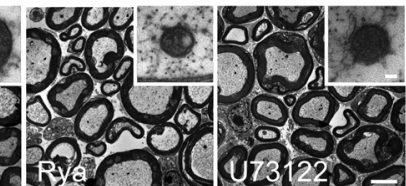

is
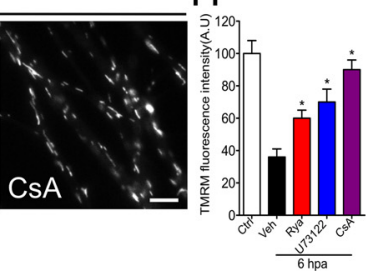

6 hpa in vitro

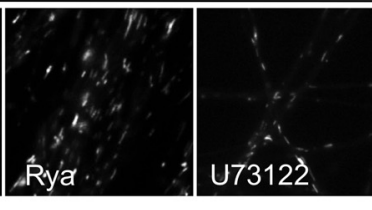
$6 \mathrm{hpa}$

Figure 5. Pharmacological inhibition of ER calcium channels protects against mitochondrial swelling. $\boldsymbol{A}, \boldsymbol{D}$, Representative electron micrographs of non-damaged neurites $(0 \mathrm{~h})$ and explants incubated for 1 or $3 \mathrm{~d}$ in vehicle (Veh) or ER calcium channels blockers Rya and U73122 or Ru360. Inhibition of ER channels or the mitochondrial uniporter prevents mitochondrial swelling at 24

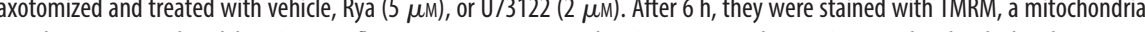
列 MRM fluorescence in each condition normalized to control ( $n=9,3$ images per sample, 3 samples per condition, 3 repetitions; ${ }^{*} p<0.05$ by Student's $t$ test compared with vehicle; error bars indicate SEM).

\section{Axonal ER is closely apposed to mitochondria and axoplasmic membrane}

The ER is a multifunctional organelle responsible for protein synthesis and folding, vesicular trafficking, lipid biosynthesis, and calcium storage (Voeltz et al., 2002). In peripheral axons, the ER forms a continuous network of irregular tubules and cisternae (Tsukita and Ishikawa, 1976). To elucidate the participation of the ER in axonal degeneration, we undertook a detailed characterization of its structure and potential association with other intra-axonal organelles using a $3 \mathrm{D}$ reconstruction of the axonal ER, mitochondria, and axolemma by serial sectioning and electron microscopy (EM). Longitudinal serial sections of sciatic nerve myelinated axons showed that the ER forms a continuous network of smooth tubules of a constant diameter (Fig. 4A-C). Regularly, specializations of this structure are observed in the form of accumulation of vesicles (Fig. 4D). In addition, part of this ER network appears in close proximity to the axonal plasma membrane (Fig. 4A,B). When mitochondria were reconstructed along with the ER, regions of close proximity, $<0.1 \mu \mathrm{m}$, between these two organelles were found (Fig. $4 E, F$ ).

These morphological data demonstrate that a continuous ER network is closely apposed with the axonal plasma membrane and mitochondria, an association that might provide a means for efficient communication between these organelles and also could be important during degenerative processes. 
A $0 d$
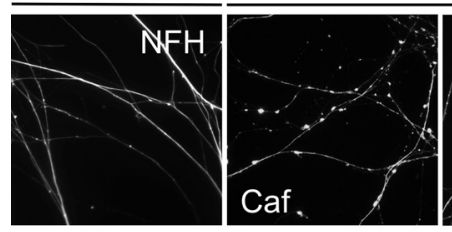

$2 \mathrm{~d}$ in vitro
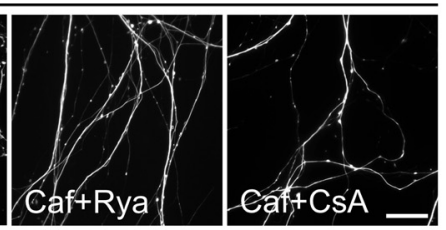

C
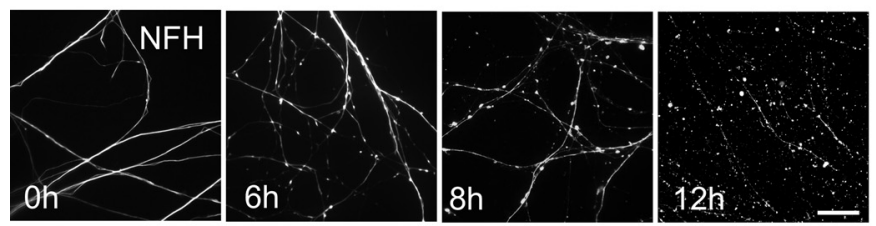

\section{$\mathrm{D}$}
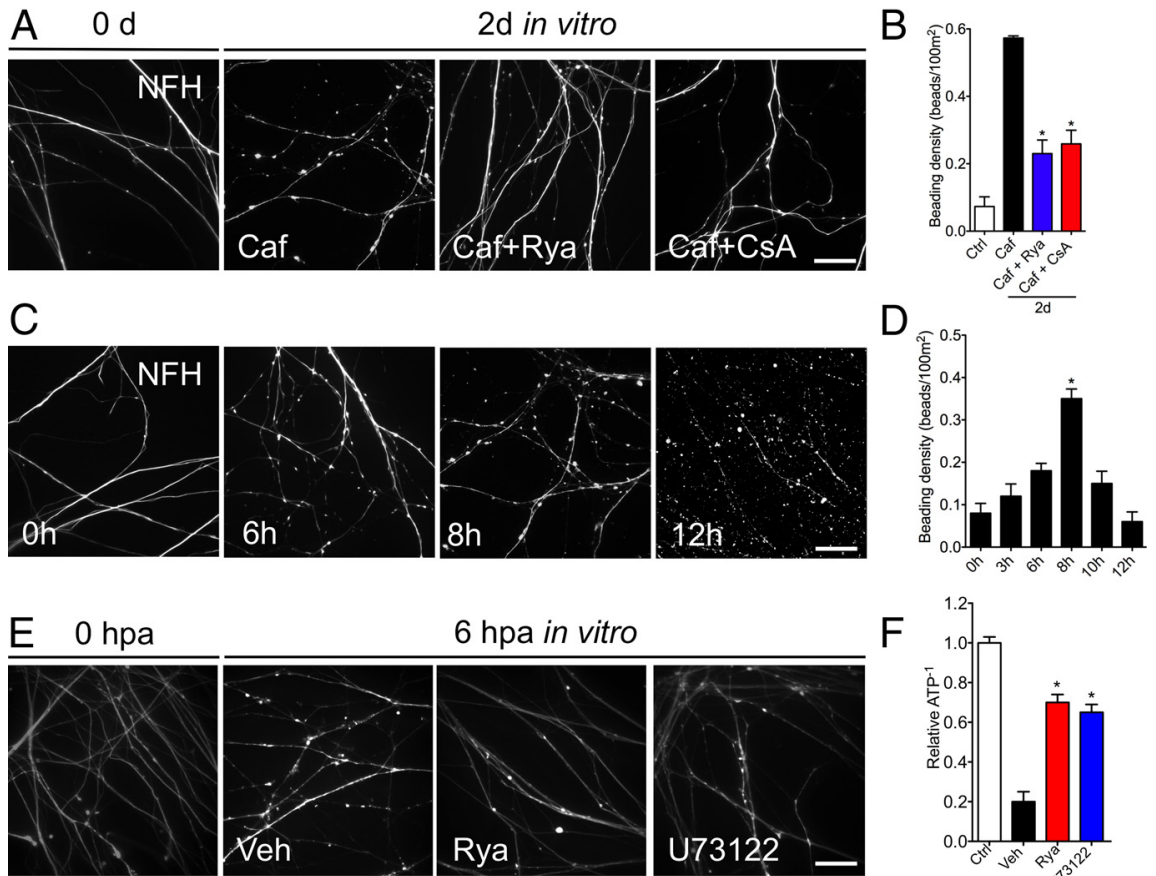

6 hpa in vitro

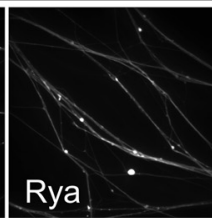

Figure 6. Activation of RyaR triggers axonal degeneration, which is rescued by Rya or mPTP inhibition. $A$, Embryonic DRG cultures treated with caffeine (Caf, $10 \mathrm{~mm})$, an activator of RyaR, caffeine plus Rya $(5 \mu \mathrm{M})$, or caffeine plus CsA (20 $\mu \mathrm{M})$ for $48 \mathrm{~h}$. Caffeine alone induces the appearance of axonal beadings, a degeneration-like phenotype. Either Rya or CsA rescues this beaded phenotype. $\boldsymbol{B}$, Quantification of the beading density in cultures treated as in $\boldsymbol{A}(n=9,3$ images per sample, 3 samples per condition, 3 repetitions; ${ }^{*} p<0.05$ by Student's $t$ test compared with $48 \mathrm{~h}$ of caffeine; error bars indicate SEM). Scale bar, $50 \mu \mathrm{m}$. C, Time course of beading in vitro. Embryonic DRGs were axotomized and immunostained for NFH at 3, 6, 8, 10, and $12 \mathrm{~h}$. At $6 \mathrm{hpa}$, a degenerated phenotype that shows beads in the neurites start to appear. At $8 \mathrm{hpa}$, the beading phenotype is clear. Scale bar, 50 $\mu \mathrm{m}$. D, Quantification of beading after axotomy at different times, with a significant increase in beading at $8 \mathrm{hpa}$ observed when compared with non-injured neurites ( $n=3$ per each group; ${ }^{*} p<0.05$ by Student's $t$ test compared with control; error bars indicate SEM). $\boldsymbol{E}, \boldsymbol{F}$, Embryonic DRGs were axotomized and treated with vehicle (Veh), Rya (5 $\mu \mathrm{M})$, or U73122 (2 $\mu \mathrm{M})$. After $6 \mathrm{~h}$, they were stained with MgGreen, an ATP-sensitive dye. $\boldsymbol{E}$, MgGreen fluorescence in non-injured DRG neurites or 6 hpa DRGs treated with vehicle solution, Rya, or U73122. After axotomy, fluorescence increases, denoting a drop in ATP levels. Both Rya and U73122 inhibit the axotomy-induced fluorescence increase. Scale bar, $50 \mu \mathrm{m}$. $\boldsymbol{H}$, Quantification of MgGreen fluorescence in each condition shown as the reciprocal of the signal in each condition normalized to control (relative ATP ${ }^{-1} ; n=9,3$ images per sample, 3 samples per condition, 3 repetitions; ${ }^{*} p<0.05$ by Student's $t$ test compared with vehicle; error bars indicate SEM).

\section{Inhibition of ER calcium channels prevents mPTP opening} We showed previously that axonal degeneration is mediated by opening of the mPTP (Barrientos et al., 2011). Mitochondrial calcium overload and oxidative stress are known to be major activators of the mPTP (Halestrap et al., 1997; Bernardi et al., 2006). Increase in mitochondrial calcium was detected $9 \mathrm{hpa}$ and preceding the cytosolic increase (LoPachin and Lehning, 1997). The source of this early increase in mitochondrial calcium remains unknown, but the increase in axoplasmic calcium that we see from ER release appears to precede this change in mitochondrial swelling (Fig. 1E). Also, depletion of intracellular calcium stores protects against axonal degeneration under ischemic conditions (Stys, 2005), and ER stress induces calcium-dependent permeability transition, mitochondrial outer membrane permeabilization, and apoptosis (Deniaud et al., 2008). Thus, the axonal ER network, which is in close proximity to mitochondria in axons (Fig. 5), is a likely source of mitochondrial swelling.

To determine whether ER-derived calcium activates the mPTP after axonal injury, we used EM to test for mitochondrial swelling in sciatic nerve explants incubated with ER channel blockers or vehicle for 24 and $72 \mathrm{~h}$. This mitochondrial swelling is an ultrastructural consequence of mPTP opening (Vial, 1958; Webster, 1962). At 24 h, a small amount of vehicle-treated axons
F

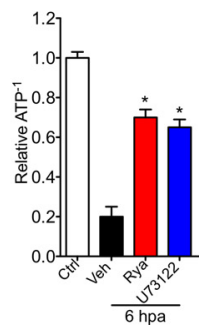

show signs of degeneration, and nerve explants incubated for $72 \mathrm{~h}$ in vehicle solution consist mainly of degenerated axons with collapsed myelin sheaths (Fig. 5A), consistent with our immunofluorescence data (Fig. 2A). As expected, in vehicleincubated nerve explants, mitochondrial diameter increase was observed at $24 \mathrm{~h}$ in vitro with progressive enlargement up to 72 h (Fig. 5 A, B,E; Barrientos et al. 2011). The nerve explants incubated with Rya or U73122 for 24 and $72 \mathrm{~h}$ showed axonal protection at the EM level (Fig. $5 A, D$ ). At 24 h, Rya- or U73122-treated nerve explants showed mitochondrial diameters similar to contralateral $(0 \mathrm{~h})$ nerves (Fig. $5 A, B)$. Reduction of mitochondrial swelling was also observed in explants treated for $72 \mathrm{~h}$ with these drugs (Fig. $5 D, E$ ). Inhibition of the uniporter-mediated calcium entry into mitochondria by Ru360 also inhibited mitochondrial swelling and axonal degeneration at the EM level and by immunofluorescence analysis (data not shown).

mPTP opening leads to loss of the mitochondrial membrane potential (Halestrap, 2009). CsA prevents mPTP opening by binding to the MPTP regulatory protein Cyclophilin-D (Barrientos et al., 2011). Thus, we asked whether RyaR and $\mathrm{IP}_{3} \mathrm{R}$ inhibition might prevent loss of mitochondrial membrane potential in anucleated axons using the mitochondrial membrane potential indicator TMRM. Axotomy results in a profound loss of mitochondrial membrane potential, with a $50 \%$ reduction of TMRM fluorescence at 6 hpa when compared with intact DRGs (Fig. 5G). Conversely, in anucleated axons that were treated with Rya or U73122, the decrease in TMRM fluorescence was partially inhibited (Fig. $5 H$ ). Importantly, after CsA treatment, the injury-induced decrease in TMRM fluorescence was also inhibited (Fig. 5G,H).

Together, these EM and TMRM imaging data strongly suggest that activation of both RyaR and $\mathrm{IP}_{3} \mathrm{R}$ after axotomy participates in MPTP opening that leads to axotomy-induced Wallerian degeneration.

Calcium release from the ER leads to axonal degeneration by activating the MPTP

To determine whether there is a functional association between the axonal ER and mPTP in axonal degeneration, we used caffeine to directly activate RyaR in DRG cultures, and axonal degeneration was evaluated in conditions in which $\mathrm{mPTP}$ opening was pharmacologically inhibited. Caffeine treatment of intact sensory neuron cultures for $48 \mathrm{~h}$ led to extended beading along axons, suggesting damage to these processes (Fig. 6A). Importantly, beading was prevented by inhibition of RyaR (Fig. 6A). This suggests that the axonal beading injury that caffeine treatment elicited is through activation of the RyaR. This beading process appears to be a part of the injury-induced degeneration 
program, because axotomized neurites also exhibit beaded axons between 6 and 8 hpa (Fig. 6C,D).

To test for participation of the MPTP in caffeine-induced axonal damage, we treated DRG cultures with a combination of caffeine to activate RyaR and CsA to inhibit MPTP opening. Interestingly, the mPTP inhibition with CsA significantly decreased axonal beading in caffeinetreated neurons (Fig. 6A,B). We next assessed the impact of axonal damage in mitochondrial function by measuring ATP levels. We used the MgGreen assay, which indirectly measures the change in cellular ATP concentration, with ATP reduction seen as an increase in fluorescence intensity (Baggaley et al., 2008; Persson et al., 2013). Axotomy led to increased signal intensity of MgGreen in neurites, indicating reduced levels of cellular ATP compared with non-injured neurites (Fig. 6E,F). After both Rya and U73122 treatments, the reduction of ATP levels triggered by axotomy were partially inhibited at 6 hpa (Fig. $6 E, F$ ).

These results demonstrate that ERderived calcium directly contributes to mitochondrial dysfunction in the axonal compartment and suggest that ER-derived calcium triggers mPTP opening in mitochondria during the early stages of axonal injury. This event likely leads to a second phase of injury/degeneration that is associated with mitochondrial dysfunction and protease activation.

\section{Inhibition of ER calcium release protects against axotomy- induced oxidative stress}

Both calcium and reactive oxidative species (ROS) can activate the mPTP (Halestrap, 2009). This can lead to successive release of calcium and ROS production (Court and Coleman, 2012). Increasing the neuronal antioxidant capacity was shown to protect from injury-induced axonal degeneration (Calixto et al., 2012).

Because we demonstrated a functional relationship between ER-derived calcium release and $\mathrm{MPTP}$ opening (Figs. 5, 6), we asked whether ROS production might depend on this ERdependent process. To this end, we fluorometrically measured superoxide levels in DRG neurites in vitro after axotomy and in DRGs treated with ER and mitochondrial calcium channels inhibitors. After axotomy, a strong increase in superoxide levels was detected at $6 \mathrm{~h}$ (Fig. $7 A, C$ ). This precedes the decay in neurofilament immunostaining that was seen $12 \mathrm{hpa}$ (Fig. 2C), so it likely represents an early event in axonal degeneration. Treatment with the antioxidant Trolox or mPTP inhibition using CsA abolished the increase in superoxide levels triggered by axotomy (Fig. 7B). This demonstrates that oxidative stress is downstream of mPTP opening during axonal degeneration.

In this context, the axotomy-induced calcium release from the ER could be modulating the observed increase in oxidative stress. To test this possibility, we evaluated superoxide levels in anucleated axons in which the RyaR or $\mathrm{IP}_{3} \mathrm{R}$ were inhibited. Anucleated neurites treated with Rya or U73122 showed superoxide levels comparable with nondamaged neurites (Fig. $7 A-C$ ). Finally, neurites treated with the mitochondrial calcium uniporter using Ru360 also showed no rise in superoxide levels after axotomy (Fig. $7 A-C)$. These results indicate that the increase in oxidative stress after axotomy depends on calcium release from the ER, most likely downstream mPTP opening after mitochondrial calcium uptake.

\section{Discussion}

Axonal degeneration is an early feature of several neurodegenerative conditions, but the sequence of events leading to this axonal loss is still unknown. The role of calcium in this degenerative process has long been accepted, but there is no detailed understanding of the calcium source(s) and dynamics. Chelation of extracellular calcium protects against axonal degeneration triggered by axotomy (George et al., 1995), and depletion of intracellular calcium stores protects against axonal degeneration under ischemic conditions (Stys, 2005). We showed previously that a crucial event during axonal degeneration is the opening of the MPTP (Barrientos et al., 2011), which is highly dependent on calcium levels (Halestrap et al., 1986). The data that we present here establishes that the release of ER-derived calcium store is a critical step in Wallerian degeneration by activating the MPTP that leads to axonal loss.

Our results show that chelation of external calcium can protect from neurofilament degradation and axonal disintegration but not mitochondrial swelling (Fig. $1 A, B$ ). Conversely, calcium from internal stores probably regulates a step upstream of $\mathrm{mPTP}$ opening, suggesting that there are two calcium-dependent steps during axonal degeneration: one in which $\mathrm{MPTP}$ is activated primarily by calcium from internal stores and a later step downstream of mitochondrial dysfunction in which proteases are activated primarily by extracellular calcium.

Local ER calcium was implicated previously in degeneration only in an ischemic injury paradigm (Stys, 2005), but the participation of mitochondria as an intermediate stage has not been evaluated. Consistent with the observations in ischemic axonal injury, degeneration of axons after both mechanical- and toxicinduced axonal injuries was attenuated by pharmacological inhibition and genetic knockdown of the ER calcium channels RyaR 


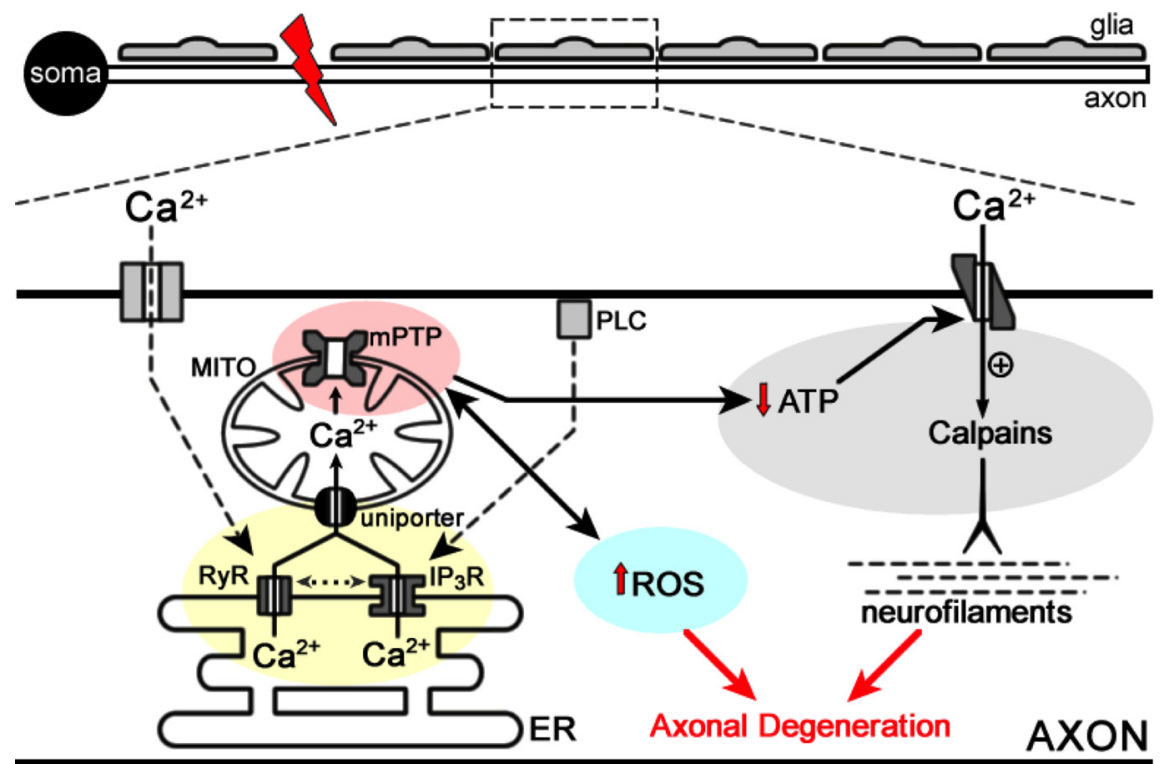

Figure 8. Model of ER participation in axonal degeneration. Schematic representation of a neuron with soma and its axon. A mechanical injury (red bolt) isolates the axon and disrupts calcium equilibrium in the axon. Activation of voltage (discontinuous line to RyR) and metabotropic channels (discontinuous line to $\mathbb{P}_{3} R$ ) in the axonal plasma membrane can induce ER calcium release by RyaR and $\mathbb{P}_{3} R$. Calcium release from the ER is buffered by associated mitochondria (MIT0; continuous black line). Crosstalk between RyaR and IP ${ }_{3} R$ (dotted line) might explain that inhibition of one ER channel might affect the release efficiency of the other one. Alternatively, the efficiency of calcium release can be compromised with only one functional channel. Mitochondrial calcium overload results in mPTP opening, which leads to calcium overload in the axon, increase in ROS generation (black line between mPTP and ROS; red arrow shows increase), and decrease in ATP production (black arrow from mPTP to ATP; red arrow shows decrease), which changes the direction of the $\mathrm{Na}^{2+} / \mathrm{Ca}^{2+}$ antiporter and additional calcium enters from the extracellular space (black arrow), which potentially induces cytoskeleton disintegration through calpain activation.

and $\mathrm{IP}_{3} \mathrm{R}$ (Fig. 2). The mechanism of axonal degeneration during ischemia probably involves a decrease in axonal ATP and dysregulation of ionic composition, leading to membrane depolarization and intra-axonal calcium overload (Stys, 2004). Membrane depolarization during pathological conditions was shown to activate voltage-sensitive calcium channels, and inhibition of L- or $\mathrm{N}$-type channels partially protects against anoxic and traumatic axonal injury (Fern et al., 1993; Imaizumi et al., 1999; Wolf et al., 2001; Ouardouz et al., 2006).

Inhibition of either RyaR or $\mathrm{IP}_{3} \mathrm{R}$ attenuated axonal degeneration triggered by both mechanical and toxic insults (Fig. 2) to approximately equivalent degrees. Studies in smooth muscle and cardiomyocytes demonstrated that activation of $\mathrm{IP}_{3} \mathrm{R}$ can contribute to RyaR-mediated calcium signaling, shaping the spatial distribution and kinetic properties of calcium sparks in these cells (Gordienko and Bolton, 2002; Zhang et al., 2003; Mackenzie et al., 2004; Zima and Blatter, 2004; Li et al., 2005; Domeier et al., 2008). Also, it was described recently that RyaR-mediated calcium sparks in skeletal muscle fibers are suppressed by pharmacological or genetic inhibition of $\mathrm{IP}_{3} \mathrm{R}$ channels (Tjondrokoesoemo et al., 2013). Our data are consistent with a functional link between these channels and suggest that activation of both RyaR and $\mathrm{IP}_{3} \mathrm{R}$ are required to trigger the downstream degenerative cascade that results in axonal mPTP opening. Therefore, the inhibition of one ER channel in the axons could affect the release efficiency of the other axonal ER channel. It was suggested that the ER contains two distinct calcium storage compartments: one associated with calcium release through the RyaR and the other associated with calcium release through the $\mathrm{IP}_{3} \mathrm{R}$ (Bian et al., 1991; Berridge, 1993; Tanaka and Tashjian, 1993; Tribe et al., 1994). Therefore, the amount of calcium released by only one channel after pharmacological or genetic inhibition of the other channel type might not be sufficient to reach the threshold for mPTP opening. More work will be required to clearly establish the interplay between axonal RyaR and $\mathrm{IP}_{3} \mathrm{R}$ for axonal pathophysiology.

After axotomy or toxic damage, inhibition of mPTP opening prevents axon degeneration (Barrientos et al., 2011). Mitochondrial swelling, a well established reporter of mPTP opening, can be seen in axons within $\sim 12 \mathrm{~h}$ after injury (Barrientos et al., 2011). Here, we showed that blocking ER channels prevented this mitochondrial swelling up to $72 \mathrm{hpa}$ (Fig. 5). Also, the RyaR agonist caffeine can trigger axonal degeneration by itself, but MPTP inhibition using CsA prevents caffeineinduced axonal degeneration (Fig. 6). This places the ER calcium release as a critical regulator of mitochondrial dysfunction by mPTP opening.

We and others showed previously that increase in oxidative stress is a key and early step in axonal degeneration (Press and Milbrandt, 2008; Fischer and Glass, 2010; Calixto et al., 2012; O’Donnell et al., 2013). Consistent with these observations, ROS levels increase as early as $6 \mathrm{hpa}$ in isolated axons. It was shown that an increase in mitochondrial calcium levels induces ROS production in a physiological context (Peng and Jou, 2010), and mitochondria depolarization leads to an increase in ROS production (Murphy, 2009). Thus, mPTP opening induced by ER-derived calcium will lead to an increase in ROS production, creating a feedforward loop of mitochondrial calcium overload, mPTP opening, and ROS production (Court and Coleman, 2012). Accordingly, inhibition of mPTP with CsA delays the axotomy-induced increase in ROS levels in axons, which is consistent with a proposed role for the $\mathrm{MPTP}$ as a regulator of mitochondrial calcium and ROS (Peng and Jou, 2010).

Putting the sum of our data together with previous studies generates a model in which early calcium release from ER triggers mPTP opening and disruption of mitochondrial function. This disruption eventually increases ROS and leads to additional calcium release and entry, triggering protease activation and cytoskeletal degradation (Fig. 8). A deeper understanding of the interplay between the ER and mitochondrion crosstalk will clearly be necessary to determine how to break the feedforward mechanism that results in additional calcium release and eventual degeneration of the axon.

Although the functional role for the ER in the axonal compartment has not been studied extensively, early morphological data showed an extensive ER network in axons (Droz et al., 1975; Tsukita and Ishikawa, 1976). Our 3D EM reconstructions are consistent with this report but also show that the axonal ER is closely juxtaposed to both mitochondria and the axolemma. These ultrastructural data suggest that axonal mitochondria may be topographically situated to readily take up calcium released by ER channels after axonal damage. Specialized ER membrane subdomains that regulate ER-to-mitochondria communication, referred to as mitochondria-associated ER membranes (MAM), 
were defined in other cellular systems (Fujimoto and Hayashi, 2011). These structures trigger take up of calcium into the mitochondrial lumen directly from $\mathrm{IP}_{3} \mathrm{R}$ or RyaR at the ER (Kirichok et al., 2004; Fujimoto and Hayashi, 2011). It will be interesting to determine whether such MAMs are also present in the axonal domain. Mutations in proteins responsible for maintaining the ER structure were demonstrated in hereditary spastic paraplegias (Park et al., 2010), and mutations in mitofusin 2 leads to an axonal form of Charcot-Marie-Tooth disease (CMT); this protein was shown to tether the ER to mitochondria (de Brito and Scorrano, 2008). Axonal degeneration is seen in both the hereditary spastic hereditary paraplegias and axonal CMTs (Kijima et al., 2005; Chen and Chan, 2006), so the ER-to-mitochondrial signaling that we define here could contribute to axon degeneration in human neurodegeneration. Additional work will be needed to determine whether the ERto-mitochondrial calcium signaling uncovered here is relevant for the axonal loss in these and other neurodegenerative disorders. Nonetheless, it is intriguing to speculate that the active participation of the ER in axonal degeneration through early calcium release leading to mitochondrial dysfunction may provide new therapeutic targets for neuroprotection.

\section{References}

Adalbert R, Morreale G, Paizs M, Conforti L, Walker SA, Roderick HL, Bootman MD, Siklós L, Coleman MP (2012) Intra-axonal calcium changes after axotomy in wild-type and slow Wallerian degeneration axons. Neuroscience 225:44-54. CrossRef Medline

Araki T, Sasaki Y, Milbrandt J (2004) Increased nuclear NAD biosynthesis and SIRT1 activation prevent axonal degeneration. Science 305:10101013. CrossRef Medline

Baggaley EM, Elliott AC, Bruce JI (2008) Oxidant-induced inhibition of the plasma membrane $\mathrm{Ca}^{2+}$-ATPase in pancreatic acinar cells: role of the mitochondria. Am J Physiol Cell Physiol 295:C1247-C1260. CrossRef Medline

Barrientos SA, Martinez NW, Yoo S, Jara JS, Zamorano S, Hetz C, Twiss JL, Alvarez J, Court FA (2011) Axonal degeneration is mediated by the mitochondrial permeability transition pore. J Neurosci 31:966-978. CrossRef Medline

Bernardi P (2013) The mitochondrial permeability transition pore: a mystery solved? Front Physiol 4:95. CrossRef Medline

Bernardi P, Krauskopf A, Basso E, Petronilli V, Blalchy-Dyson E, Di Lisa F, Forte MA (2006) The mitochondrial permeability transition from in vitro artifact to disease target. FEBS J 273:2077-2099. CrossRef Medline

Berridge MJ (1993) Inositol trisphosphate and calcium signalling. Nature 361:315-325. CrossRef Medline

Bian JH, Ghosh TK, Wang JC, Gill DL (1991) Identification of intracellular calcium pools. Selective modification by thapsigargin. J Biol Chem 266: 8801-8806. Medline

Blattner JR, He L, Lemasters JJ (2001) Screening assays for the mitochondrial permeability transition using a fluorescence multiwell plate reader. Anal Biochem 295:220-226. CrossRef Medline

Broekemeier KM, Carpenter-Deyo L, Reed DJ, Pfeiffer DR (1992) Cyclosporin A protects hepatocytes subjected to high $\mathrm{Ca}^{2+}$ and oxidative stress. FEBS Lett 304:192-194. CrossRef Medline

Calixto A, Jara JS, Court FA (2012) Diapause formation and downregulation of insulin-like signaling via DAF-16/FOXO delays axonal degeneration and neuronal loss. PLoS Genet 8:e1003141. CrossRef Medline

Chappell JB, Crofts AR (1965) Calcium ion accumulation and volume changes of isolated liver mitochondria. Calcium ion-induced swelling. Biochem J 95:378-386. Medline

Chen H, Chan DC (2006) Critical dependence of neurons on mitochondrial dynamics. Curr Opin Cell Biol 18:453-459. CrossRef Medline

Cheng LZ, Lü N, Zhang YQ, Zhao ZQ (2010) Ryanodine receptors contribute to the induction of nociceptive input-evoked long-term potentiation in the rat spinal cord slice. Mol Pain 6:1. CrossRef Medline

Coleman MP, Freeman MR (2010) Wallerian degeneration, wld(s), and nmnat. Annu Rev Neurosci 33:245-267. CrossRef Medline

Court FA, Coleman MP (2012) Mitochondria as a central sensor for axonal degenerative stimuli. Trends Neurosci 35:364-372. CrossRef Medline

Court FA, Hewitt JE, Davies K, Patton BL, Uncini A, Wrabetz L, Feltri ML
(2009) A laminin-2, dystroglycan, utrophin axis is required for compartmentalization and elongation of myelin segments. J Neurosci 29:39083919. CrossRef Medline

Crompton M, Costi A (1988) Kinetic evidence for a heart mitochondrial pore activated by $\mathrm{Ca}^{2+}$, inorganic phosphate and oxidative stress. A potential mechanism for mitochondrial dysfunction during cellular $\mathrm{Ca}^{2+}$ overload. Eur J Biochem 178:489-501. CrossRef Medline

de Brito OM, Scorrano L (2008) Mitofusin 2 tethers endoplasmic reticulum to mitochondria. Nature 456:605-610. CrossRef Medline

Deniaud A, Sharaf el dein O, Maillier E, Poncet D, Kroemer G, Lemaire C, Brenner C (2008) Endoplasmic reticulum stress induces calciumdependent permeability transition, mitochondrial outer membrane permeabilization and apoptosis. Oncogene 27:285-299. CrossRef Medline

Dent MA, Raisman G, Lai FA (1996) Expression of type 1 inositol 1,4,5trisphosphate receptor during axogenesis and synaptic contact in the central and peripheral nervous system of developing rat. Development 122: 1029-1039. Medline

Domeier TL, Zima AV, Maxwell JT, Huke S, Mignery GA, Blatter LA (2008) IP3 receptor-dependent $\mathrm{Ca}^{2+}$ release modulates excitation-contraction coupling in rabbit ventricular myocytes. Am J Physiol Heart Circ Physiol 294:H596-H604. CrossRef Medline

Droz B, Rambourg A, Koenig HL (1975) The smooth endoplasmic reticulum: structure and role in the renewal of axonal membrane and synaptic vesicles by fast axonal transport. Brain Res 93:1-13. CrossRef Medline

Du H, Guo L, Fang F, Chen D, Sosunov AA, McKhann GM, Yan Y, Wang C, Zhang H, Molkentin JD, Gunn-Moore FJ, Vonsattel JP, Arancio O, Chen JX, Yan SD (2008) Cyclophilin D deficiency attenuates mitochondrial and neuronal perturbation and ameliorates learning and memory in Alzheimer's disease. Nat Med 14:1097-1105. CrossRef Medline

Fern R, Ransom BR, Stys PK, Waxman SG (1993) Pharmacological protection of CNS white matter during anoxia: actions of phenytoin, carbamazepine and diazepam. J Pharmacol Exp Ther 266:1549-1555. Medline

Fischer LR, Glass JD (2010) Oxidative stress induced by loss of $\mathrm{Cu}, \mathrm{Zn}$ superoxide dismutase (SOD1) or superoxide-generating herbicides causes axonal degeneration in mouse DRG cultures. Acta Neuropathol 119:249-259. CrossRef Medline

Forte M, Gold BG, Marracci G, Chaudhary P, Basso E, Johnsen D, Yu X, Fowlkes J, Rahder M, Stem K, Bernardi P, Bourdette D (2007) Cyclophilin D inactivation protects axons in experimental autoimmune encephalomyelitis, an animal model of multiple sclerosis. Proc Natl Acad Sci U S A 104:7558-7563. CrossRef Medline

Fujimoto M, Hayashi T (2011) New insights into the role of mitochondriaassociated endoplasmic reticulum membrane. Int Rev Cell Mol Biol 292: 73-117. CrossRef Medline

George EB, Glass JD, Griffin JW (1995) Axotomy-induced axonal degeneration is mediated by calcium influx through ion-specific channels. J Neurosci 15:6445-6452. Medline

Gordienko DV, Bolton TB (2002) Crosstalk between ryanodine receptors and $\mathrm{IP}(3)$ receptors as a factor shaping spontaneous $\mathrm{Ca}(2+)$-release events in rabbit portal vein myocytes. J Physiol 542:743-762. CrossRef Medline

Halestrap AP (2009) What is the mitochondrial permeability transition pore? J Mol Cell Cardiol 46:821-831. CrossRef Medline

Halestrap AP, Quinlan PT, Whipps DE, Armston AE (1986) Regulation of the mitochondrial matrix volume in vivo and in vitro. The role of calcium. Biochem J 236:779-787. Medline

Halestrap AP, Woodfield KY, Connern CP (1997) Oxidative stress, thiol reagents, and membrane potential modulate the mitochondrial permeability transition by affecting nucleotide binding to the adenine nucleotide translocase. J Biol Chem 272:3346-3354. CrossRef Medline

Heermann S, Spittau B, Zajzon K, Schwab MH, Krieglstein K (2012) Schwann cells migrate along axons in the absence of GDNF signaling. BMC Neurosci 13:92. CrossRef Medline

Hunter DR, Haworth RA, Southard JH (1976) Relationship between configuration, function, and permeability in calcium-treated mitochondria. J Biol Chem 251:5069-5077. Medline

Ikegami K, Koike T (2003) Non-apoptotic neurite degeneration in apoptotic neuronal death: pivotal role of mitochondrial function in neurites. Neuroscience 122:617-626. CrossRef Medline

Imaizumi T, Kocsis JD, Waxman SG (1999) The role of voltage-gated $\mathrm{Ca}^{2+}$ channels in anoxic injury of spinal cord white matter. Brain Res 817:8492. CrossRef Medline

Kijima K, Numakura C, Goto T, Takahashi T, Otagiri T, Umetsu K, Hayasaka 
K (2005) Small heat shock protein 27 mutation in a Japanese patient with distal hereditary motor neuropathy. J Hum Genet 50:473-476. CrossRef Medline

Kirichok Y, Krapivinsky G, Clapham DE (2004) The mitochondrial calcium uniporter is a highly selective ion channel. Nature 427:360-364. CrossRef Medline

Kremer JR, Mastronarde DN, McIntosh JR (1996) Computer visualization of three-dimensional image data using IMOD. J Struct Biol 116:71-76. CrossRef Medline

Li X, Zima AV, Sheikh F, Blatter LA, Chen J (2005) Endothelin-1-induced arrhythmogenic $\mathrm{Ca}^{2+}$ signaling is abolished in atrial myocytes of inositol1,4,5-trisphosphate(IP3)-receptor type 2-deficient mice. Circ Res 96: 1274-1281. CrossRef Medline

LoPachin RM, Lehning EJ (1997) Mechanism of calcium entry during axon injury and degeneration. Toxicol Appl Pharmacol 143:233-244. CrossRef Medline

Lopez-Verrilli MA, Picou F, Court FA (2013) Schwann cell-derived exosomes enhance axonal regeneration in the peripheral nervous system. Glia 61:1795-1806. CrossRef Medline

Mackenzie L, Roderick HL, Berridge MJ, Conway SJ, Bootman MD (2004) The spatial pattern of atrial cardiomyocyte calcium signalling modulates contraction. J Cell Sci 117:6327-6337. CrossRef Medline

Martin LJ, Gertz B, Pan Y, Price AC, Molkentin JD, Chang Q (2009) The mitochondrial permeability transition pore in motor neurons: involvement in the pathobiology of ALS mice. Exp Neurol 218:333-346. CrossRef Medline

Murphy MP (2009) How mitochondria produce reactive oxygen species. Biochem J 417:1-13. CrossRef Medline

O’Donnell KC, Vargas ME, Sagasti A (2013) WldS and PGC-1alpha regulate mitochondrial transport and oxidation state after axonal injury. J Neurosci 33:14778-14790. CrossRef Medline

Ouardouz M, Malek S, Coderre E, Stys PK (2006) Complex interplay between glutamate receptors and intracellular $\mathrm{Ca}^{2+}$ stores during ischaemia in rat spinal cord white matter. J Physiol 577:191-204. CrossRef Medline

Park SH, Zhu PP, Parker RL, Blackstone C (2010) Hereditary spastic paraplegia proteins REEP1, spastin, and atlastin-1 coordinate microtubule interactions with the tubular ER network. J Clin Invest 120:1097-1110. CrossRef Medline

Peng TI, Jou MJ (2010) Oxidative stress caused by mitochondrial calcium overload. Ann N Y Acad Sci 1201:183-188. CrossRef Medline

Persson AK, Kim I, Zhao P, Estacion M, Black JA, Waxman SG (2013) Sodium channels contribute to degeneration of dorsal root ganglion neurites induced by mitochondrial dysfunction in an in vitro model of axonal injury. J Neurosci 33:19250-19261. CrossRef Medline

Pozzan T, Rizzuto R, Volpe P, Meldolesi J (1994) Molecular and cellular physiology of intracellular calcium stores. Physiol Rev 74:595-636. Medline

Press C, Milbrandt J (2008) Nmnat delays axonal degeneration caused by mitochondrial and oxidative stress. J Neurosci 28:4861-4871. CrossRef Medline

Ross CA, Danoff SK, Schell MJ, Snyder SH, Ullrich A (1992) Three additional inositol 1,4,5-trisphosphate receptors: molecular cloning and differential localization in brain and peripheral tissues. Proc Natl Acad Sci U S A 89:4265-4269. CrossRef Medline

Saalfeld S, Cardona A, Hartenstein V, Tomančák P (2010) As-rigid-aspossible mosaicking and serial section registration of large ssTEM datasets. Bioinformatics 26:i57-i63. CrossRef Medline

Saalfeld S, Fetter R, Cardona A, Tomancak P (2012) Elastic volume reconstruction from series of ultra-thin microscopy sections. Nat Methods 9:717-720. CrossRef Medline

Sasaki Y, Vohra BP, Lund FE, Milbrandt J (2009) Nicotinamide mononucleotide adenylyl transferase-mediated axonal protection requires enzymatic activity but not increased levels of neuronal nicotinamide adenine dinucleotide. J Neurosci 29:5525-5535. CrossRef Medline

Schindelin J, Arganda-Carreras I, Frise E, Kaynig V, Longair M, Pietzsch T, Preibisch S, Rueden C, Saalfeld S, Schmid B, Tinevez JY, White DJ, Hartenstein V, Eliceiri K, Tomancak P, Cardona A (2012) Fiji: an open-source platform for biological-image analysis. Nat Methods 9:676-682. CrossRef Medline

Schinzel AC, Takeuchi O, Huang Z, Fisher JK, Zhou Z, Rubens J, Hetz C, Danial NN, Moskowitz MA, Korsmeyer SJ (2005) Cyclophilin D is a component of mitochondrial permeability transition and mediates neuronal cell death after focal cerebral ischemia. Proc Natl Acad Sci U S A 102:12005-12010. CrossRef Medline
Schlaepfer WW (1974) Calcium-induced degeneration of axoplasm in isolated segments of rat peripheral nerve. Brain Res 69:203-215. CrossRef Medline

Schlaepfer WW, Bunge RP (1973) Effects of calcium ion concentration on the degeneration of amputated axons in tissue culture. J Cell Biol 59:456 470. CrossRef Medline

Schlaepfer WW, Hasler MB (1979) Characterization of the calciuminduced disruption of neurofilaments in rat peripheral nerve. Brain Res 168:299-309. CrossRef Medline

Schoenmann Z, Assa-Kunik E, Tiomny S, Minis A, Haklai-Topper L, Arama E, Yaron A (2010) Axonal degeneration is regulated by the apoptotic machinery or a NAD+-sensitive pathway in insects and mammals. J Neurosci 30:6375-6386. CrossRef Medline

Spadari S, Focher F, Kuenzle C, Corey EJ, Myers AG, Hardt N, Rebuzzini A, Ciarrocchi G, Pedrali-Noy G (1985) In vivo distribution and activity of aphidicolin on dividing and quiescent cells. Antiviral Res 5:93-101. CrossRef Medline

Stys PK (2004) White matter injury mechanisms. Curr Mol Med 4:113-130. CrossRef Medline

Stys PK (2005) General mechanisms of axonal damage and its prevention. J Neurol Sci 233:3-13. CrossRef Medline

Stys PK, Ransom BR, Waxman SG, Davis PK (1990) Role of extracellular calcium in anoxic injury of mammalian central white matter. Proc Natl Acad Sci U S A 87:4212-4216. CrossRef Medline

Tanaka Y, Tashjian AH Jr (1993) Functional identification and quantitation of three intracellular calcium pools in GH4C1 cells: evidence that the caffeine-responsive pool is coupled to a thapsigargin-resistant, ATPdependent process. Biochemistry 32:12062-12073. CrossRef Medline

Tjondrokoesoemo A, Li N, Lin PH, Pan Z, Ferrante CJ, Shirokova N, Brotto M, Weisleder N, Ma J (2013) Type 1 inositol $(1,4,5)$-trisphosphate receptor activates ryanodine receptor 1 to mediate calcium spark signaling in adult mammalian skeletal muscle. J Biol Chem 288:2103-2109. CrossRef Medline

Tribe RM, Borin ML, Blaustein MP (1994) Functionally and spatially distinct $\mathrm{Ca}^{2+}$ stores are revealed in cultured vascular smooth muscle cells. Proc Natl Acad Sci U S A 91:5908-5912. CrossRef Medline

Tsao JW, George EB, Griffin JW (1999) Temperature modulation reveals three distinct stages of Wallerian degeneration. J Neurosci 19:4718-4726. Medline

Tsukita S, Ishikawa H (1976) Three-dimensional distribution of smooth endoplasmic reticulum in myelinated axons. J Electron Microsc (Tokyo) 25:141-149. Medline

Vial JD (1958) The early changes in the axoplasm during wallerian degeneration. J Biophys Biochem Cytol 4:551-555. CrossRef Medline

Voeltz GK, Rolls MM, Rapoport TA (2002) Structural organization of the endoplasmic reticulum. EMBO Rep 3:944-950. CrossRef Medline

Wallace TL, Johnson EM Jr (1989) Cytosine arabinoside kills postmitotic neurons: evidence that deoxycytidine may have a role in neuronal survival that is independent of DNA synthesis. J Neurosci 9:115-124. Medline

Waller A (1850) Experiments on the section of the glossopharyngeal and hypoglossal nerves of the frog, and observations of the alterations produced thereby in the structure of their primitive fibres. Philos Trans R Soc Lond 140:423-429.

Webster HD (1962) Transient, focal accumulation of axonal mitochondria during the early stages of wallerian degeneration. J Cell Biol 12:361-383. CrossRef Medline

Wolf JA, Stys PK, Lusardi T, Meaney D, Smith DH (2001) Traumatic axonal injury induces calcium influx modulated by tetrodotoxin-sensitive sodium channels. J Neurosci 21:1923-1930. Medline

Zhang WM, Yip KP, Lin MJ, Shimoda LA, Li WH, Sham JS (2003) ET-1 activates $\mathrm{Ca}^{2+}$ sparks in PASMC: local $\mathrm{Ca}^{2+}$ signaling between inositol trisphosphate and ryanodine receptors. Am J Physiol Lung Cell Mol Physiol 285:L680-L690. Medline

Zheng JQ, Kelly TK, Chang B, Ryazantsev S, Rajasekaran AK, Martin KC, Twiss JL (2001) A functional role for intra-axonal protein synthesis during axonal regeneration from adult sensory neurons. J Neurosci 21:92919303. Medline

Zima AV, Blatter LA (2004) Inositol-1,4,5-trisphosphate-dependent $\mathrm{Ca}(2+)$ signalling in cat atrial excitation-contraction coupling and arrhythmias. J Physiol 555:607-615. CrossRef Medline

Ziv NE, Spira ME (1995) Axotomy induces a transient and localized elevation of the free intracellular calcium concentration to the millimolar range. J Neurophysiol 74:2625-2637. Medline 